Ranadewa, K.A.T.O., Sandanayake, Y.G. and Siriwardena, M. (2018). "Enabling Lean among Small and Medium Enterprise (SME) Contractors in Sri Lanka" In: Proc. $26^{\text {th }}$ Annual Conference of the International. Group for Lean Construction (IGLC), González, V.A. (ed.), Chennai, India, pp. 392-401. DOI: doi.org/10.24928/2018/0428. Available at: www.iglc.net.

\title{
ENABLING LEAN AMONG SMALL AND MEDIUM ENTERPRISE (SME) CONTRACTORS IN SRI LANKA
}

\author{
Ranadewa, K.A.T.O. ${ }^{1}$, Sandanayake, Y.G. ${ }^{2}$, and Mohan Siriwardena ${ }^{3}$
}

\begin{abstract}
Lack of sufficient attention to the possible benefits of adopting lean concept has hindered the performance of small and medium enterprise (SME) contractors in Sri Lanka. Insufficient knowledge on minimising non-value adding activities (NVAA) is considered as the major barrier to implementing lean. Moreover, there is a lack of empirical research identifying NVAA, in order to trigger lean adoption in Sri Lankan SME contractors. Hence, the paper investigates NVAA, their significance and the causes, which hinder lean implementation in Sri Lankan SME contractors. A literature review, followed by five case studies were carried out, and the data were analysed using 5-why analysis. According to findings, lean construction is still a relatively unfamiliar approach among SME contractors in Sri Lanka. Some organisations follow lean techniques in an ad-hoc manner without an adequate understanding of the concept. The studyfurther identified defects, inventory and waiting as major NVAA categories relevant to SME contractors. Lack of finance, insufficient training, cultural inertia, lack of individual capacities, lack of networking and collaboration, and lack of action learning were identified as the root causes for NVAA of SME contractors. Although respondents expressed their willingness to implement lean to enhance value, they identified lack of capacities as a major constraint against enabling lean adoption among SME contractors in Sri Lanka.
\end{abstract}

\section{KEYWORDS}

SME Contractors, Lean Construction, Case Studies, Sri Lanka.

\section{INTRODUCTION}

SMEs form a significant pillar of the construction industry in many economies. Although the challenges of lean implementation in construction and solutions to overcome them have been previously explored (Shang \& Pheng, 2014; Jadhav, Mantha \& Rane, 2014; Aziz, \& Hafez, 2013; Bertelsen \& Koskela, 2004; Ogunbiyi, Oladapo \& Goulding, 2013)

1 PhD Candidate, Department of Building Economics, University of Moratuwa, Sri Lanka, +94772266488, tharushar@uom.lk

2 Senior Lecturer, Department of Building Economics, University of Moratuwa, Sri Lanka, +94112650738ysandanayake@uom.1k

3 Senior Lecturer, Department of Built Environment, Liverpool John Moores University, United Kingdom, +44(0)1512312867, M.L.Siriwardena@1jmu.ac.uk 
in construction industry, there is a dearth of research on lean implementation in construction SMEs in Sri Lanka. In order to successfully implement lean in construction SMEs, it is essential to identify NVAA, which is the first principle of lean construction (Koskela, 1992). Hence, this paper focuses on identification of NVAA and their causes, which hinder lean implementation in Sri Lankan SME contractors.

This paper commences by introducing construction SMEs in Sri Lankan context and importance of lean construction to overcome their challenges. Thereafter, it discusses the NVAA in typical construction projects. Next section presents analysis of empirical data used to identify the wastes and there causes for SME contractors in Sri Lanka. The paper contributes to the body of lean construction knowledge, in particular identification of priority areas for improving lean adoption in Sri Lankan SME contractors.

\section{LITERATURE REVIEW}

\section{SMALL AND MEDIUM ENTERPRISES IN CONSTRUCTION INDUSTRY}

SMEs act as the main pillar of a booming economy of a country, an engage the prevalent portion of the workforce (Woschke, Haase \& Lautenschläger, 2016), particularly the construction SMEs. Construction SMEs consist of more than $70 \%$ of the workforce in a country (Harvie, 2004; Saleem, 2010; Emine, 2012). Similarly, Sri Lankan construction SMEs play a significant role in the economy providing job opportunities similar to large construction companies (Ranadewa, Sandanayake \& Siriwardena, 2015). Balachandra (2014) specified that the majority of registered contractors fall into the category of SME in the Sri Lankan construction industry. Yet, there is no published definition for construction SMEs in Sri Lanka. However, the category of SMEs in Sri Lankan service sector includes firms with less than 300 employees and less than SLRs 750 (approximately US\$ 5) Million annual turnover (Ministry of Industry and Commerce, 2014). Althoughthe contribution of Sri Lankan construction SMEs is vital, there is a lack of published evidence on the number of employees to define SMEs in the construction industry. Hence, a definition was developed based on the service sector annual turnover and the Construction Industry Development Authority (CIDA) Sri Lanka registration for construction contractors in Sri Lanka. Accordingly, medium-sized contractors were categorised under whose annual turnover is in between SLRs 250 - 750 (approximately US\$ 2 - 5) Million (Grade C3-C2) and small-sized contractors having an annual turnover between SLRs 16 - 250 (approximately US\$ 0.1 - 2) Million (Grade C6-C4).

\section{CHALLENGES FACE BY CONSTRUCTION SMES AND WAY FORWARD}

Ofori and Toor (2012) identified the risks faced by construction SMEs in developing countries as lack of job continuity, the deficiencies in construction industry, difficulties in operating environment of the industries, access to finance, competition from SMEs. Moreover, researchers (Rymaszewska, 2014 and Chiarini, 2012) added lack of technology, uncooperative government laws, absence of skilled workers and expertise as constant issues faced by them. Hence, there is a need for construction SMEs to adapt to changing environments (Ofori \& Toor, 2012), be able to improve their creativity, develop their networks and aim to develop and implement new construction processes yielding higher value at lower costs (Bertelsen \& Koskela, 2004). 
The conventional systems used in the industry pursue the task of project completion, however, neglected minimisation of NVAA to maximise value (Koskela et al., 2014). Therefore, construction SMEs need to hunt for techniques, concepts and strategies, while increasing the value addition. Correspondingly, organisations are pursuing to maximise value addition through embedding lean (Nesensohn, et al., 2014). Further, lean noted as one of the best approaches for improving value (Aziz \& Hafez, 2013). However, Howell \& Ballard (1998) specified that moving towards lean needed a twist in the rationale to do construction as well as the management of construction. SMEs can also be benefited by converting to lean organisations, by adjusting their processes (Rymaszewska, 2014). Although, a number ofresearchand successful application of lean can be found in the global construction context, research on lean application in Sri Lankan construction industry is limited to a few initiatives in the past (Senaratne and Wijesiri (2008); Senaratne, Ekanayake \& Siriwardena (2010); Thilakarathna \& Senaratne (2012). Although Researchers highlighted the importance of implementing lean,it is still in its infancy in construction SMEs. Therefore, there is a need to investigate the nature of lean implementation in SME contractors in Sri Lanka. Investigation of the extent to which NVAA are identified by SMEs in Sri Lankan construction is a starting point in this regard.

\section{NON-VALUE-ADDING ACTIVITIES (NVAA)}

Waste is known as NVAA in the lean construction lexicon (Emuze \& Saurin, 2016). NVAA are activities that add no value as per the requirements of customers to a product or a service (Alves, Carvalho, and Sousa, 2012). Womack and Jones (2003) defined it as any activity thatuses resources without value creation. Construction Industry Institute noted that 57\% NVAA and 10\% value addition in the construction industry, whereas manufacturing industry has 62\% Value addition and 26\% NVAA (Mossman, 2009). Hence, the construction industry needs to maximise the value while removing the NVAA.

Removal of NVAA is a fundamental concept of lean construction and one of the most efficient ways of enhancing capacities and improving the profitability of an organisation (Koskela, 1992; Ranadewa, Sandanayake \& Siriwardena, 2017). They were categorised into seven areas namely overproduction, overstocking, unnecessary movements, waiting, transportation, over processing and defects (Ohno, 1988; Ogunbiyi, et al., 2013). Nevertheless, Alves et al. (2012) referred to non-utilization of human potential as the eighth waste by considering Green's (1999) critique ofthe negligence of human stress as a waste. Hence, identification of these eight types of wastes and addressing them accordingly will help enable lean. Antosz and Stadnicka (2017) noted that $49 \%$ of the responded organisations agreed that waiting for material as the major waste. They also reported that $41 \%$ of organisationswanted to remove unnecessary movements and $39 \%$ wanted to remove machine failures by implementing lean. Moreover, Alarcon et al. (2001) highlighted the importance of exploring the root causes of waste. This fact has been further proven by a study carried out by Sri Lankan researchers (Kulatunga,et al., 2006), which identified root causes of waste in design decisions, methods of construction or even with attitudes of people. According to Alwi, Hampson and Mohamed (2002), waiting time, especially for instructions, lack of design and documentation contribute to NVAA during the construction process, representing a lack of human resources skills. 
Gavilan and Bernold (1994) added that issues in design, material management, procurement, and processes, as the causes of NVAA. As suggested by Howell \& Ballard (1998), waste is a cost that could have been avoided within the activities, such as rework, or cost due to extended activity duration along the critical path. Hence, this will affect both costas well as the time duration. This highlights the importance of identifying and reducing the NVAA in the construction projects. However, the underlying nature of waste in the construction industry is not clearly visible compared to manufacturing and production. Similarly, neither NVAA nor VAA to enable lean in organizations have been explored in detail with reference to construction SMEs in Sri Lanka. Therefore, there is a need to explore the root causes of NVAAs in the construction SMEs in Sri Lanka.

\section{RESEARCH METHODOLOGY}

This research aimed to investigate NVAA, their significance and the causes, which hinder lean implementation in Sri Lankan SME contractors. Hence, a literature review was carried out to explore the theoretical identification of NVAA in the construction industry and in particular within SME contractors. Multiple case studies were conducted to explore the NVAA in Sri Lankan construction SMEs. The profile of the case study SME contractors are summarised in following Table 1.

Table 1 Profile of the case study organisations used for the research

\begin{tabular}{|c|c|c|c|c|c|}
\hline & Case A & Case B & Case C & Case D & Case E \\
\hline Grade & $\mathrm{C} 2$ & $\mathrm{C} 2$ & $\mathrm{C} 4$ & $\mathrm{C} 4$ & C6 \\
\hline Size & Medium & Medium & Small & Small & Small \\
\hline $\mathrm{Nr}$ of Employees & 50 & 60 & 45 & 20 & 20 \\
\hline $\mathrm{Nr}$ of Projects & 11 & 05 & 04 & 03 & 03 \\
\hline Years of exp. & 34 & 15 & 22 & 10 & 06 \\
\hline Field of activity & Building & Building & Building & Building & Building \\
\hline \multirow[t]{5}{*}{ Respondents } & - Chairman & - Managing & - Managing & - Chairman & - Managing \\
\hline & - Project & Director & Director & - Project & Director \\
\hline & Manager & - Project & - Technical & manager & - Technical \\
\hline & - Site & Manager & Officer & - Technical & $\begin{array}{l}\text { Offlcer } \\
\text { - Technical }\end{array}$ \\
\hline & Engineer & $\begin{array}{l}\text { - Site } \\
\text { Engineer }\end{array}$ & $\begin{array}{l}\text { - Technical } \\
\text { Officer }\end{array}$ & Officer & $\begin{array}{l}\text { Technical } \\
\text { Officer }\end{array}$ \\
\hline
\end{tabular}

The empirical data collection methods adopted within the case studies were, semistructured interviews with project participants, non-participant observations of progress meetings and study of substantial of the project (tender documents, meeting minutes).Employing semi-structured interview method is preferred in qualitative approach (Edwards \& Holland, 2013) since the respondents have a structured flow to ask questions from interviewees. Three respondents from each case were interviewed.

All five SME contractors represented different approaches and strategies to identify NVAA in their projects. Hence, the data from case studies were collected and analysed using 5-whys analysis to identify commonalities from their diverse experiences. Ohno (1988) specified that the 5-Whys technique was developed and fine-tuned within the Toyota Motor Corporation as a critical component of its problem-solving training to 
determine the root cause of a defect or problem by repeating the question 'Why?'. Correspondingly, Ohno (1988) specified that often root causes are hidden under more obvious symptoms, and only by unpeeling the layers of the problem can the root be found. Similarly, Tommelein (2015) highlighted the importance of going to the gemba and repeatedly asking Why to explore the root cause to improve the system. Murugaiah et al. (2010) specified that the application of the 5-whys analysis provides a fact-based and structured approach to problem identification and correction focuses on both reducing \& eliminating NVAA. Hence, 5-whys analysis was used to identify the root causes.

\section{RESEARCH FINDINGS}

NVAA identified in the construction projects were categorised into eight types. The root causes of them were identified using 5-whys analysis and the findings are presented in Figure 1. Each factor is presented with $(\mathrm{X} / \mathrm{Y})$ values. $\mathrm{X}$ represents the number of causes (incoming arrows) each factor is responsible for and $\mathrm{Y}$ represents the number of effects (outgoing arrows) created by each factor, in order to identify the significance.

\section{WHY 1}

Findings of the case studies identified 29activitiesthat can be attributed to the eight types of NVAA in construction projects done by SMEs. As per the findings, inventory, waiting, defects and skills misuse are the most significant types of NVAA in construction SMEs, as they have 5, 4 and 7 outgoing arrows respectively. Waste due to defects was considered as significant by both top management and middle management as it directly affects both cost and time of the project. Getting the employees to reach their full potential at work under stressful conditions is a tough challenge (Dobre, 2013). Similarly, the respondents emphasized that people are working 1-2 levels below their true capability and this caused the waste of skill utilisation. Though top management has thoroughly emphasized that learning from one site being used well on another, site engineers disagree. In their opinion, they are losing learning opportunities due to high workload.

According to responded project managers, neither overproduction nor over processing has been a major issue for construction SMEs. However, the analysis of project documents revealed evidence of some level of overproduction and over processing in almost all the projects. Yet, the project managers have not been clearly identified them as waste. The research identified case A as the company with the highest lean maturity which has less NVAA. Case D was identified as the company with lowest lean maturity where the employees themselves unaware of the steps involvedin the processes. However, the presented data is not sufficient to provide justification for the lean maturity as it involves further studies. Consequently, most significant effects were the factors which cause more NVAA in the project (a large number of outgoing arrows as per the Figure 1). Correspondingly, the research identified delay in delivering material (9), cost of moving to and from storage (9), unnecessary movement of people and equipment (13), walking between different workplaces (12), taking unnecessary steps (11), work done to fill the gaps (9), not meeting specifications first time (8), time overrun and missed deadlines (12) and losing time and skills improvements (12) as the major effects. 


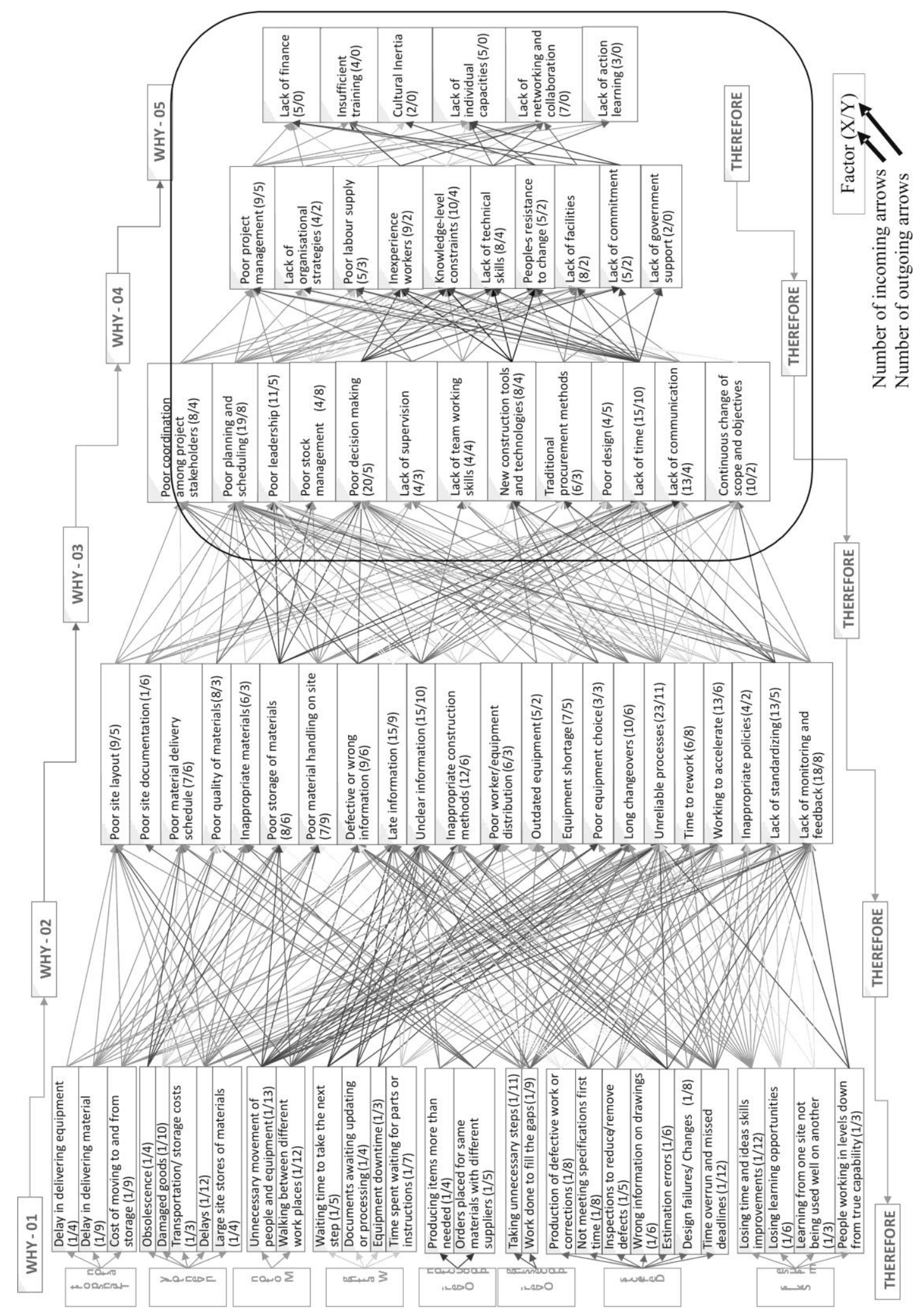

Figure 1: 5-whys analysis for NVAA in construction projects of SMEs 
As the next step, (WHY 2) the reasons for the identified causes were explored.

\section{WHY 2}

The discussed 29 causes of NVAA can be attributed to individually or in a combination of 22 factors as shown in Figure 1.Out of them, 10 factors; poor site layout(9), defective or wrong information(9), late information(15), unclear information(15), inappropriate construction methods(12), long changeovers(10), unreliable processes(23), working to accelerate(13), lack of standardizing(13) and lack of monitoring and feedback(18) considered as the most significant causes for ' $W H Y$ 2'. As construction SMEs are limited to small projects or subcontracting projects of large organisations, they have to wait for information, resulting in significant waste. Correspondingly, the pressure caused by large organisations compel SMEs to accelerate their work, which leads to generate more waste. The respondents emphasized that long changeovers (which received 10 arrows in Figure 1)is another reason for them to accelerate their work. Lack of standardising, lack of monitoring and feedback within SME organisations have worsened the situation. Use of inappropriate construction methods was identified as another significant cause as part of ' $W H Y$ 2'. Hence, the processes turn out to be unreliable. Out of the 22 causing factors, most significant effects were poor material handing on site(9), late information(9), unclear information(10), unreliable processes(11), and lack of monitoring and feedback(8).Causes of these factors were examined during the next stage (WHY 3 ) of the overall analysis.

\section{WHY 3}

Most of the factors to answer ' $W H Y$ 3' were caused by poor planning and scheduling(19), poor decision making(20), poor leadership(11), lack of time(15), lack of communication(13) and continuous change of scope and objectives(10). Further, the respondents have added poor coordination among project stakeholders, poor stock management, too late supervision, lack of team working skills, new construction tools and technologies, traditional procurement methods and poor design to this list of causes. Yet the most significant effects are the lack of time (10) and poor planning and scheduling (8) out of the 13 factors identified during the empirical study. Therefore, the study further questioned 'why' during the next phase to identify the root causes.

\section{WHY 4}

The respondents, in particular, the middle managementemphasized that lack of effective project management skills and methodology (9) and lack of organisational strategies (4) as the main causes. However, top management contended that lack of workers (5), inexperienced workers (9), knowledge-level constraints (10), lack of technical skills(8), lack of commitment (5) and people's resistance to change (5) as the significant causes to answer 'WHY 4' in Figure 1.The respondents further specified that the lack of facilities (8) as a major cause and bureaucracy (2) as an uncontrollable cause for theabove-listed waste. However, knowledge-level constraints (4), lack of technical skills workers (4) and lack of effective project management methodology (5) were the most significant effects, which required more attention from construction SMEs. 


\section{WHY 5}

According to research findings, lack of finance (5), insufficient training (4), cultural inertia (2), lack of individual capacities (5), lack of networking and collaboration (7) and lack of action learning (3) were identified as the root causes at the end of 5-why analysis. Networking and collaboration will offer construction SMEs the opportunity to learn new trends and technologies in the construction market and get expert opinions to overcome NVAA in their construction organisations. However, unlike large construction organisations, construction SMEs lack capacities in networking and collaboration, which caused the most significant root cause for the majority of wastes. Serpell et al (1995) specified that the waste occurs due to controllable and uncontrollable root causes. Correspondingly some of the listed root causes are controllable, whereas some are uncontrollable. Most of the SME contractors take no notice of NVAA arising due to preventable internal causes; hence miss the opportunity to reduce the cost of the project. The main uncontrollable cause is the cultural inertia when comparing to other lean implemented countries. People resist changing their attitudes towards construction due to cultural inertia. However, appropriate change management strategies have the potential to address the above-mentioned cultural inertia. All other listed root causes are controllable.

The causes identified under 'WHY 3', 'WHY 4' and 'WHY 5'collectively can be considered the major causes and should inform the development of capacities necessary for an organisation to implement lean (refer the causes within the red outlined area in Figure 1). Hence, construction SMEs in Sri Lanka require identifying the gaps in their organisations' capacities to reduce NVAA. Therefore, efforts towards capacity building for construction SMEs is an important step to overcome the NVAA.

\section{CONCLUSION \& RECOMMENDATIONS}

This paper investigated the significance of NVAA and their causes of SME contractors in Sri Lanka. A literature review followed by five case studies were carried out to collect data. NVAA identified in the construction projects were categorisedinto 8 types and identified the root causes of them using 5-whys analysis.

The findings highlightthat lack of finance, insufficient training, cultural inertia, lack of individual capacities, lack of networking and collaboration and lack of action learning as the root causes for the generation of NVAA in Sri Lankan construction SMEs. However, Sri Lankan construction SMEs have not adequately identified the majority of their NVAA and their causes. Hence, the research findings will guide construction SMEs to understand the importance of identification of NVAA in construction projects. It will further pave the way towards the identification of root causes to their wastes and address them accordingly. This study further proves that a detailed understanding of the processes and extensive explorations of all possible causes using the 5-whys analysis will reduce NVAA. In addition, it was also evident that inexpensive or zero cost solutions could be implemented to reduce NVAA. Hence, construction SMEs in Sri Lanka needs to find a way to overcome the controllable root causes using '02 Hows' as per the lean lexicon. This will pave the way for further research of this study. Some respondents already expressed their willingness to implement lean to overcome NVAA of their organisations. Yet, the research findings evidenced lack of capacities as a major constraint against 
enabling lean adoption among SME contractors in Sri Lanka. Hence, the research findings will pave the path to identify the capacities necessary to reduce NVAA among SME contractors, which will be the focus of the next phase of this research.

\section{REFERENCES}

Alarcon, L., Grillo, A., Freire, J. andDiethelm, S. (2001)."Learning From Collaborative Benchmarking in the Construction Industry."Proc. of the 9th Ann. Conf. of the Int'l Group for Lean Const'n. Singapore.

Alves, A.C., Carvalho, J.D., and Sousa, R.M. (2012). "Lean production as promoter of thinkers to achieve companies' agility". The Learning Organisation, 19(3), 219-237.

Alwi, S., Hampson, K. and Mohamed, S. (2002)."Non-value-adding activities in Australian construction projects". Proc. of the Int'l conf. on Advancement in Design, Const'n, Const'nMgt and Maintenance of Building Structure,270-278.

Antosz, K. andStadnicka, D. (2017). "Lean philosophy implementation in SMEs - study results”. Procedia Engineering, 182, 25-32. Doi.org/10.1016/j.proeng.2017.03.107.

Aziz, R.F. andHafez, S.M. (2013). "Applying lean thinking in construction and performance improvement". Alexandria Engineering J., 52(2013), 679-695.

Balachandra, H.K. 2014. "Sri Lanka country report". Proc. of $20^{\text {th }}$ Asia construct conf', 1314, Hong Kong.

Bertelsen,S.and Koskela, L. (2004). "Const'n beyond lean: new understanding of const'nmgt". Proc. of the 12th Ann. Conf. of the Int'l Group for Lean Const'n, Denmark.

Chiarini, A. (2012). "Lean production: mistakes and limitations of accounting systems inside the SME sector". J. of Manufacturing Techno Mgt, 23(5), 681-700.

Dobre, O.I. 2013. "Employee motivation and organizational performance". Review of Applied Socio Economic Research, 5(1), 53-60.

Edwards, R. \&Holland,J.(2013). What is qualitative interviewing?.London: Bloomsbury.

Emine, D. (2012). "Financial challenges that impede increasing the productivity of SMEs in Arab region". Journal of Contemporary Management, 17-32.

Emuze,F.A. andSaurin,T.A. 2015.Value and waste in lean const'n. New York: Routledge.

Gavilan, R.M. and Bernold, L.E. (1994)."Source evaluation of solid waste in building construction".J. of Const'nEng and Mgt, 120(3), 536-552.

Green, S.D. (1999). "The dark side of lean construction: exploitation and ideology."Proc. of the 7th Ann. Conf. of the Int'l Group for Lean Construction. Berkeley. 21-32.

Harvie, C. (2004). East Asian SME capacity building, competitiveness and market opportunities in a global economy. Working Paper, 04-16, University of Wollongong.

Howell, G. and Ballard, G. (1998). "Implementing lean construction: understanding and action". Proc. of the 6th Ann. Conf. of the Int'l Group for Lean Co'n. Guarujá, Brazil.

Jadhav, J.R., Mantha, S.S. and Rane, B. (2014). Exploring barriers in lean implementation. Int Journal of Lean Six Sigma, 5(2), 122-148.

Koskela, L. (1992). Application of the new production philosophy to construction. Center for Integrated Facility Engineering, 1-81. https://doi.org/Technical Report No. 72.

Koskela, L.J., Howell, G.A., Ballard, G.and Tommelein, I. (2014). The foundations of lean construction. In Design and construction: building in value , Butterworth Heinemann, Oxford, UK, 211-226. 
Kulatunga, U., Amaratunga, D., Haigh, R. andRameezdeen, R. (2006). "Attitudes \& perceptions of const'n workforce on const'n waste in SL".Mgt of Env'talQlty: An Int'l J., 17(1), 57-72.

Ministry of Industry and commerce Sri Lanka. (2015). National policy framework for SME development. Colombo: Ministry of Industry and Commerce Sri Lanka.

Mossman, A. (2009). Creating value: a sufficient way to eliminate waste in lean design and lean production. Lean Construction Journal. 13-23.

Murugaiah, U., Benjamin, S.J., Marathamuthu, M.S. \&Muthaiyah, S. 2010. "Scrap loss reduction using the 5-whys analys".Int'l J. of Qlty\& Reliability Mgt, 27(5), 527-540.

Nesensohn, C., Bryde, D., Ochieng, E., Fearon, D. and Hackett, V. (2014). "Assessing lean construction maturity". Proc. of the 22nd Ann. Conf. of Int'l Group for Lean Construction, Oslo, Norway, 1157-1168.

Ofori, G. and Toor, S.R. (2012). "Leadership development for construction SMES". Engineering Project Organisations Conference, Rheden, The Netherlands,1-14.

Ogunbiyi, O.E., Oladapo, A.A. and Goulding, J.S. (2013). "A review of lean concept and its application to sustainable construction in the UK". Int'lJ. of SustConst'nEng\& Technology, 4(2), 82-92.

Ohno, T. (1988), Toyota production system: Beyond large scale production. Productivity Press. Cambridge, MA.

Ranadewa, K.A.T.O., Sandanayake, Y.G. and Siriwardena, M. (2017). "What does lean capacity mean?" Proc. of the 6th World Const'n Symposium 2017, 485-494, Sri Lanka.

Ranadewa, K.A.T.O., Sandanayake, Y.G. and Siriwardena, M. (2015). "Capacity building in construction SMEs: a proposal through enabling lean". Proc. of the $8^{\text {th }}$ Int'l Conf of Faculty of Architecture Research Unit (FARU), 519-531. Sri Lanka.

Rymaszewska, A.D. (2014). "The challenges of lean manufacturing implementation in SMEs". Benchmarking: An Int'l J., 21(6), 987-1002.

Saleem, Q. (2010). "Overcoming constraints to SME development in MENA Countries and Enhancing Access to Finance". IFC Advisory Services in the MENA.

Senaratne, S., Ekanayake, S. and Siriwardena, M. (2010)."Lean Prefabrication: A Sustainable Approach".CIB 2010 Wld Cong Proc: Blding a Better World,(11),33-44.

Senaratne, S. and Wijesiri, D. (2008). "Lean construction as a strategic option: Testing its suitability and acceptability in Sri Lanka". Lean Construction J., 4(1), 34-48.

Serpell, A., Venturi, A. and Contreeas, J. (1995), Characterization of waste in building construction project", in Alarcon, L.F. (Ed.), Lean Construction, Balkema, Rotterdam.

Shang, G., \&Pheng, L.S. (2014). Barriers to lean implementation in the construction industry in China. Journal of Technology Management in China, 9(2), 155-173.

Thilakarathna, N. and Senaratne, S. (2012). "Literature review on lean implementation cases in the construction process". FARU J.:Sp Issue on EmgingBltEnv, 4, 147-162.

Tommelein, I. D. (2015).”Journey toward Lean Construction: Pursuing a Paradigm Shift in the AEC Industry". J. of Const'nEng and Mgt, 141(1970), 1-12.

Womack, J.P., and Jones, D.T. (1996). Lean thinking. New York: Simon \& Schuster.

Woschke, T., Haase, H. andLautenschläger, A. (2016). "Waste in NPD processes of German SMEs".Int'lJ. of Productivity and Performance Mgt, 65(4), 532-553. 

